particular the differences between physician and patient reported outcomes has not been analysed. High quality data from the Stent or Surgery (SOS) trial allows such an analysis.

Methods The SoS trial was a large RCT $(\mathrm{n}=988)$ comparing stentassisted percutaneous coronary intervention (PCI) with coronary artery bypass grafting $(\mathrm{CABG})$ in patients with multivessel CAD. Participation in the SoS trial included an appraisal of angina symptoms by both patient and physician according to the Canadian Cardiovascular Society (CCS) Classification System prior to, and subsequently at 6 and 12 months following coronary intervention. In this study patient and doctor reported outcomes were compared systematically. Results Paired CCS scores at baseline, 6 months and 12 months were available for 919,886 and 888 cases respectively. At baseline the overall level of agreement was good with $>75 \%$ paired data sets demonstrating a difference of $\leq \pm 1$ CCS class. Patterns of discordance change however between baseline and follow-up time points. Abstract 40 figure 1 shows the paired scores at baseline, charting the patient score and, for each CCS grade, the observed difference-doctor (D) minus patient (P). Doctors are reluctant to record scores of 0 or 4 , preferring CCS grades 2 and 3 . Thus there is little overall difference in mean CCS score (P 2.2 vs $\mathrm{D} 2.5, \mathrm{p}<0.001)$. Yet at follow-up, doctors record freedom from angina $(\mathrm{CCS}=0)$ in a more substantial proportion of the population, considerably more so than patients self-report $(p<0.0001)$ (Abstract 40 figure 2). The published results of the SOS trial used doctor gradings to report freedom from angina at 1 year in $79 \%$ of CABG patients vs $66 \%$ of PCI patients $(p<0.0001)$. If patient gradings are used instead these figures are reduced to $57 \%$ in CABG and $44 \%$ in PCI ( $<<0.0001$ ), rendering both treatment strategies significantly less effective at relieving angina from a patients perspective ( $\mathrm{p}<0.0001)$, Abstract 40 table 1 .

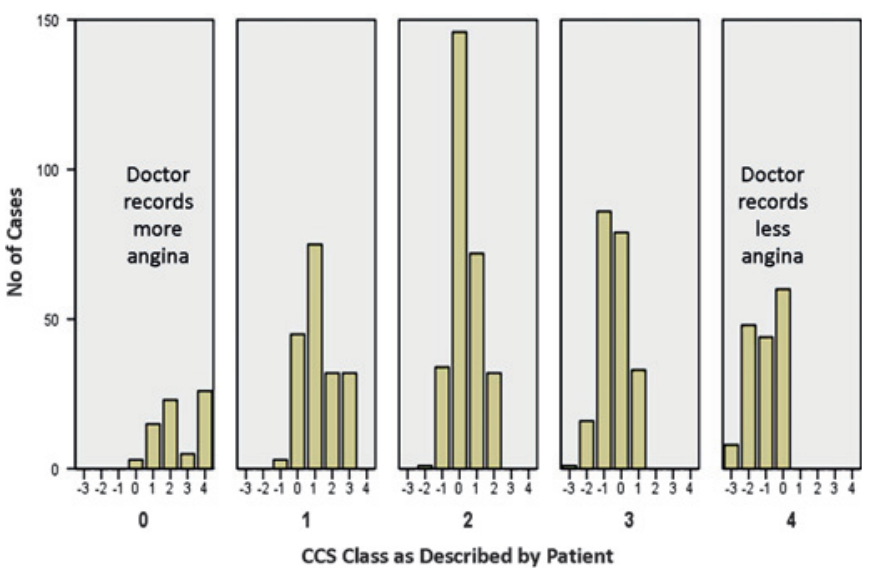

Abstract 40 Figure 1 Difference between doctor and patient classification of Angina before revascularisation.
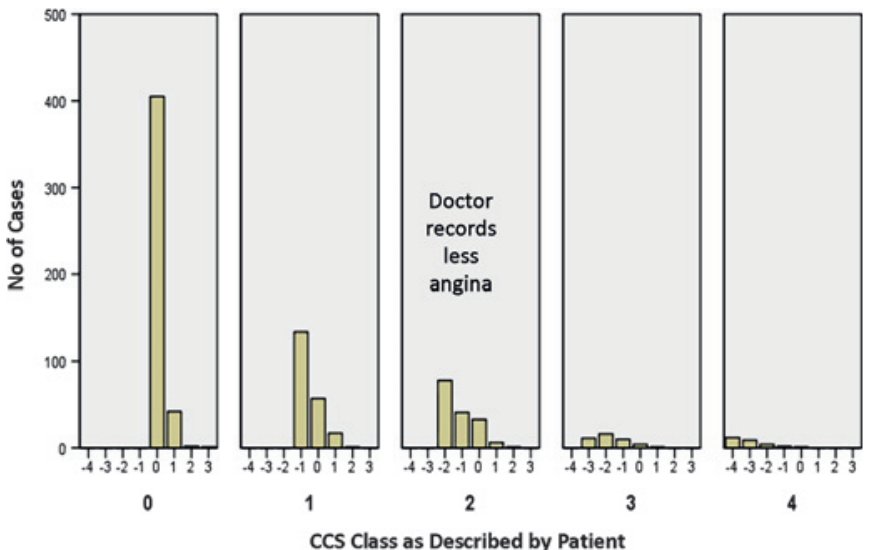

cCS Class as Described by Patient

Abstract 40 Figure 2 Difference between doctor and patient classification of Angina at $12 \mathrm{~m}$ Fup.
Abstract 40 Table 1

\begin{tabular}{llll}
\hline & PCI (\%) & CABG (\%) & p \\
\hline Doctor scoring CCS class 0 & 66 & 79 & $<0.0001$ \\
Patient scoring CCS class 0 & 44 & 57 & $<0.0001$ \\
\hline
\end{tabular}

Conclusions This is the first randomised study to compare the improvement in angina status reported by patients and clinicians following revascularisation therapy for coronary artery disease. The observed trend for doctors to insist that all patients must have some symptoms at baseline, and more importantly, to suggest that a greater proportion of patients have been rendered symptom free at follow-up (than is suggested by self-reported estimates) has important implications and may call into question our current understanding of the impact of revascularisation.

\section{REDUCED ARTERIAL WAVE REFLECTION AND ENHANCED LV RELAXATION CONTRIBUTE TO WARM-UP ANGINA}

doi:10.1136/heartjnl-2011-300198.41

${ }^{1} \mathrm{~T}$ P E Lockie, ${ }^{2} \mathrm{~A}$ Guilcher, ${ }^{3} \mathrm{C}$ Rolandi, ${ }^{1} \mathrm{D}$ Perera, ${ }^{1} \mathrm{~K}$ De Silva, ${ }^{1} \mathrm{R}$ Williams, ${ }^{3} \mathrm{M}$ Siebes, ${ }^{2} \mathrm{P}$ Chowienczyk, ${ }^{1} \mathrm{~S}$ Redwood, ${ }^{1} \mathrm{M}$ Marber. ${ }^{1}$ Rayne Institute, St Thomas Hospital, KCL,
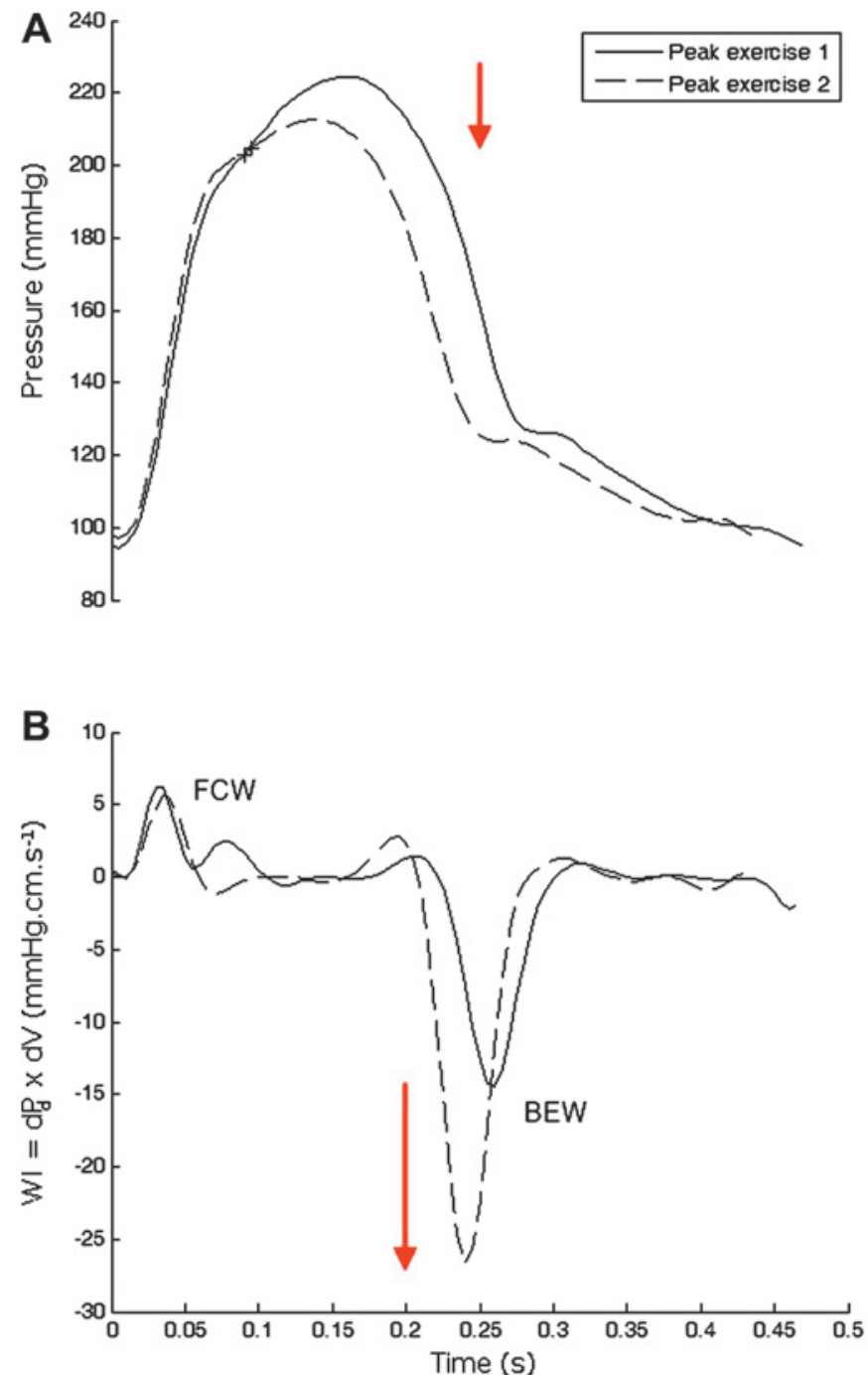

Abstract 41 Figure 1 (A) shows aortic pressure traces taken at peak exertion with a reduction in pressure augmentation during Ex2; $(B)$ shows WIA with an increase in the backward expansion, or "sucking" wave originating from the microvasculature. 
London, UK; ${ }^{2}$ Clinical Pharmacology, St Thomas Hospital, KCL, London, UK; ${ }^{3}$ Department of Bio-Engineering, University of Amsterdam, AMC, Amsterdam, The Netherlands

Background The mechanisms of the clinically observed phenomenon of reduced angina on second exertion, or warm-up angina, are poorly understood. This study compared changes in central nary blood flow during serial exercise that may contribute.

Methods and Results 16 patients ( 15 male, $61 \pm 4.3$ yrs) with a positive exercise stress test and exertional angina completed the protocol. During cardiac catheterisation via radial access they performed 2 consecutive exertions (Ex1, Ex2) using a supine cycle ergometer. Throughout exertions, distal coronary pressure $\left(\mathrm{P}_{\mathrm{d}}\right)$ and flow velocity $(V)$ were recorded in the culprit vessel using a dual sensor coronary guide wire while aortic pressure was recorded using a second wire. Time to $1 \mathrm{~mm}$ ST depression was longer in Ex2 ( $p=0.003)$ and rate pressure product $(\mathrm{RPP})$ was higher $(\mathrm{p}=0.025)$ confirming warm-up. A $33 \%$ decline in aortic wave reflection $(p<0.0001)$ in Ex2 (see Abstract 41 figure $1 \mathrm{~A}$ ) coincided with a reduction in both tension time index and diastolic time index $(p<0.0001)$. However, the latter was offset by reduced microvascular resistance $\left(\mathrm{P}_{\mathrm{d}} / V\right), \mathrm{p}=0.0002$, and enhanced left ventricular relaxation during Ex2 as suggested by a larger backwardthe intra-coronary signals. See Abstract 41 figure 1B. The energy of the forward compression wave and overall coronary blood flow, as measured by the velocity time integral, did not change.

Conclusions In patients with warm-up angina, exercise induces changes in the aortic pressure waveform, microvascular function and LV relaxation. These combine to reduce afterload without compromising myocardial diastolic blood flow thereby likely enabling improved performance on second exercise.

\section{RETROSPECTIVE CALCULATION OF SYNTAX SCORE IN 200 PATIENTS UNDERGOING ELECTIVE CORONARY ARTERY BYPASS GRAFTING (CABG) AND PERCUTANEOUS CORONARY INTERVENTION (PCI); ARE WE FOLLOWING BEST PRACTICE?}

doi:10.1136/heartjnl-2011-300198.42 haemodynamics, peripheral wave reflection and patterns of corotravelling suction wave $(p=0.01)$ on wave intensity analysis (WIA) of

Discussion The majority of patients undergoing PCI at the FRH have SYNTAX scores in the lowest tertile. There is no difference in the SYNTAX scores in patients having PCI from referral bases within the centre or from outside. In total almost one quarter of all patients undergoing CABG have a SYNTAX score in the lowest tertile. And this rises to almost one third in those patients referred from district general hospitals. Only a small number of these patients have an additional clear indication for CABG over PCI. Furthermore we found that a significant proportion of these do not go through MDT planning. These results may indicate that cardiologists are more likely to bring patients to MDT meetings than surgeons and, according to SYNTAX scoring, more patients are inappropriately having CABG than are inappropriately having PCI. Based on this data in our institution discussing all patients at an MDT and the use of SYNTAX scoring at point of referral would be more likely to increase PCI revascularisation rates.

\section{Abstract 42 Table 1}

\begin{tabular}{lllll}
\hline & $\begin{array}{l}\text { Average } \\
\text { SYNTAX } \\
\text { score }\end{array}$ & $\begin{array}{l}\text { \% Patients with } \\
\text { SYNTAX score } \\
\text { in lower third } \\
(\mathbf{0}-\mathbf{2 2})\end{array}$ & $\begin{array}{l}\text { \% Patients with } \\
\text { SYNTAX score } \\
\text { in middle third } \\
(\mathbf{2 3 - 3 2 )}\end{array}$ & $\begin{array}{l}\text { \% Patients with } \\
\text { SYNTAX score in } \\
\text { higher third (>33) }\end{array}$ \\
\hline $\begin{array}{l}\text { All Referrals for PCl } \\
14.9\end{array}$ & 84 & 11 & 5 \\
$\begin{array}{l}\text { Referrals for PCI } \\
\text { from within trust }\end{array}$ & 15.0 & 84 & 12 & 4 \\
$\begin{array}{l}\text { Referrals for PCl } \\
\text { from outside trust }\end{array}$ & 14.8 & 84 & 10 & 6 \\
\hline
\end{tabular}

Abstract 42 Table 2

\begin{tabular}{|c|c|c|c|c|}
\hline & $\begin{array}{l}\text { Average } \\
\text { SYNTAX } \\
\text { score }\end{array}$ & $\begin{array}{l}\% \text { Patients with } \\
\text { SYNTAX score } \\
\text { in lower third } \\
(0-22)\end{array}$ & $\begin{array}{l}\% \text { Patients with } \\
\text { SYNTAX score } \\
\text { in middle third } \\
(23-32)\end{array}$ & $\begin{array}{l}\% \text { Patients with } \\
\text { SYNTAX score in } \\
\text { higher third }(>33)\end{array}$ \\
\hline All Referrals for CABG & 28.8 & 24 & 40 & 35 \\
\hline $\begin{array}{l}\text { Referrals for CABG } \\
\text { from within trust }\end{array}$ & 31.0 & 19 & 34 & 47 \\
\hline $\begin{array}{l}\text { Referrals for CABG } \\
\text { from outside trust }\end{array}$ & 25.0 & 32 & 50 & 18 \\
\hline
\end{tabular}

L J Mullen, R Edwards, R Taylor, B Nyawo. Freeman Hospital, Newcastle upon Tyne

Introduction Cardiologists are generally the gatekeepers of coronary artery disease and have been much criticised for not discussing all patients being considered for revascularisation therapy at an MDT (multi-disciplinary team) meeting or not referring patients with traditional "surgical disease" for CABG. At the Freeman Hospital (FRH), a large cardiothoracic unit in the North of England, patients are typically referred for PCI or CABG by cardiologists working within the Newcastle upon Tyne Trust or from district general hospitals within the network. Patients are not routinely discussed at MDT but can be brought to the weekly meeting at the discretion of the referrer. The recently reported SYNTAX study allows objective quantification of the degree of coronary disease and facilitates an evidence based decision between CABG and PCI. This gives us the opportunity to examine whether elective revascularisation is being performed appropriately at our institution.

Methods We performed a retrospective analysis at the Freeman Hospital. 200 patients who had elective revascularisation between April 2009 and April 2010 were selected. This included 100 cases of CABG and 100 of PCI. Half of each were referrals from other hospitals. Patients' SYNTAX scores were calculated using pre-procedure angiograms. MDT meeting records and patients' notes were reviewed.

Results The average SYNTAX score for patients undergoing elective PCI was 15 , compared to 29 for those undergoing CABG. $84 \%$ of patients undergoing elective PCI had SYNTAX scores less than 22. $35 \%$ of all patients referred for elective CABG had scores greater than 33. The average SYNTAX score for CABG referrals from outside the trust was lower (25) than from within the trust (31).
PROGNOSIS AFTER PRIMARY PERCUTANEOUS CORONARY INTERVENTION FOR STEMI: CAN THE SYNTAX SCORE HELP?

doi:10.1136/heartjnl-2011-300198.43

A J Brown, L M McCormick, N E J West. Papworth Hospital, Cambridge, UK

Background Factors affecting prognosis after primary percutaneous coronary intervention (PPCI) for ST-elevation myocardial infarction (STEMI) include age at presentation, the presence of diabetes mellitus, left ventricular function and/or cardiogenic shock. Although the debate continues over a strategy of complete revascularisation (immediate or staged) vs culprit-only, little is known about the impact of the extent of coronary disease at presentation on prognosis after PPCI. The SYNTAX score, designed to stratify outcomes in multivessel PCI and CABG, has been validated in unselected populations undergoing elective PCI; to date, no studies have assessed its utility in PPCI. Methods Consecutive patients attending a single UK tertiary centre for PPCI between September 2008 and June 2010 (n=695) were included. SYNTAX scoring was performed by a single trained operator blinded to patient details and outcome. Scoring was validated by analysis of 3 separate cohorts by 2 other experienced operators. Patients were split into 3 subgroups as in the SYNTAX trial (score $\leq 22$ (low, L), 22.5-32 (intermediate, IM) and $\geq 32.5$ (high, $\mathrm{H})$ ), and patient data and outcome measures obtained by interrogation of local and national databases.

Results 671 of 695 patients were included in the analysis with 24 being excluded owing to inability to score (previous CABG, images 